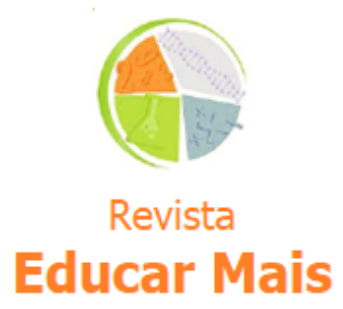

\section{O imaginário eurocentrado e o racismo institucional: a exclusão de negros/as, indígenas e quilombolas na pós-graduação de instituições públicas no país.}

\begin{abstract}
The Eurocentric Imaginary and the institutional racism: the exclusion of black people, indigenous and quilombolas in country's public institutions post graduation programs
\end{abstract}

Cláudio Baptista Carle ${ }^{1}$

\begin{abstract}
RESUMO
O texto que se apresenta é fruto de anos de dedicação aos estudos das comunidades indígenas, negras e quilombolas nas instituições do país. Um contexto histórico as coloca em um estágio diverso das outras pessoas no processo de entrada e permanência no ensino superior. Mas é forte fator de exclusão do pós-graduação no país por inúmeras razões. Razões essas que apresento aqui parcialmente a partir de alguns estudos que realizei durante minha atuação em comissões e coordenação que visa a sua integração ao universo da pós-graduação. O texto não indica as instituições e nem os cursos em que estes processos acontecem, mas ao ser lido muitos reconhecerão seus espaços. Principalmente os/as estudantes que sofreram o racismo institucional. É um texto introdutório, mas importante para esse momento histórico que vivemos no Brasil onde os direitos dessas populações são fortemente ameaçados.
\end{abstract}

Palavras-chave: racismo institucional, exclusão, diversidade.

\begin{abstract}
The text presented is the fruit of years of dedication on studies of indigenous, black and quilombola communities in the country's institutions. A historical context puts them at a different stage from other people in the process of entry and stay in higher education. Otherwise, there is a strong factor of exclusion of the graduate in the country for innumerable reasons. These reasons I present here are partially from some studies that I carried out during my work in commissions and coordination aimed at their integration into the postgraduate universe. The text does not indicate the institutions or the courses in which these processes take place, but when read many will recognize their spaces. Especially students who have suffered institutional racism. It is an introductory text, but important for this historical moment that we live in Brazil where the rights of these populations are strongly threatened.
\end{abstract}

Keywords: institutional racism, exclusion, diversity.

\footnotetext{
${ }^{1}$ UFPel - Universidade Federal de Pelotas, Pelotas/RS - Brasil.
} 


\section{O imaginário eurocentrado e o racismo institucional: a exclusão de negros/as, indígenas e quilombolas na pós-graduação de instituições públicas no país.}

"a desigualdade e a pobreza têm cor no Brasil" (Silva, 2016, p. 455).

Eu estudo as questões indígenas e afro-brasileiras desde 1987, atuei durante um tempo em comissão de ingresso de estudantes negros/as, indígenas e quilombolas em instituição de ensino superior tanto na graduação como na pós-graduação, atuei em comissão de permanência na graduação destes estudantes, realizei processos de entrada diferenciada desses estudantes, atuei como coordenador da área de inclusão e diversidade institucional e atuo ainda em comissão de diversidade de pósgraduação. Este tempo de atuação possibilitou de maneira direta, através de muitos relatos e de fatos diretos, marcados por documentação farta, a configuração de muitos casos de exclusão de estudantes, tanto em nível de graduação como em nível da pós-graduação, não por que eram "desqualificados", mas por eram caracterizados assim, por possuírem uma origem diferente dos padrões universitários do país, que é marcado por uma presença branca e de classe média e média alta. O texto não indica instituições e nem cursos específicos onde este processo vem acontecendo, mas ao ser lido muitos reconhecerão estes espaços, principalmente os/as estudantes que sofreram o racismo institucional. $O$ texto é introdutório a essa temática e se efetiva importante discutir nesse momento histórico em que vivemos no Brasil, onde os direitos dessas populações são fortemente ameaçados.

O Estatuto da Igualdade Racial indica que a população negra é o conjunto de pessoas que se autodeclaram pretas e pardas, conforme o quesito cor ou raça usado pelo IBGE ou que adotam autodefinição análoga. Essa ideia é passível de ser estendida aos indígenas e quilombolas. É sobre essas populações que o racismo institucional é imposto.

O trabalho com os Censos Demográficos produzidos pelo Instituto Brasileiro de Geografia e Estatística (IBGE), apresentam dados sobre o "perfil predominante dos aprendizes e pesquisadores brasileiros: predominantes do sudeste, brancos, de famílias com os mais altos rendimentos (...) os negros representavam $18,1 \%$ e os brancos $79,7 \%$ " (Silva, 2016, p. 454). Esta realidade ainda não mudou significativamente. Essa realidade não é exclusiva do sudeste acontece na da cidade onde resido e em todo o país. As políticas de ações afirmativas ainda são entendidas como um benefício e não como uma reparação histórica inevitável para esta sociedade excludente.

Estudei denúncias apresentadas em várias instituições do país, com qual tive contato, a partir de minha atuação na diversidade, aqui alicerçado pela aura do Imaginário (Durand, 2002) apresento os pontos relevantes a serem analisados nesses processos, considerando uma "eurocentricidade" dos servidores públicos nas motivações das exclusões realizadas.

A eurocentricidade foi foco de estudo do imaginário lusitano onde se percebeu que no próprio processo de formação da sociedade europeia a educação transformou-se em "linha de montagem" (ARAUJO e RIBEIRO, 2012, p. 52), que gera discussões hoje sobre sua continuidade, mas essa ideia influencia nossos programas de pós-graduação. A escola europeia conta a história de Pinóqui as avessas onde os estudantes entram na escola com "carne e osso" e para sair "só receberam diplomas depois de se transformarem em bonecos de pau" (ARAUJO e RIBEIRO, 2012, p. 52). Essa ironia ultrapassa a relação de uma história infantil, pois a ideia de se ter ao final "um adulto produtivo" que 
"devore a criança inútil", assim as crianças e por consequência todo o campo educativo enquadrando as pessoas, a palavra aqui tem força de um ideologema no colocar as pessoas em um quadrado, em uma forma igual para todos, "num sistema educacional rígido, formatado e sempre desconfiado do poder da imaginação" (ARAUJO e RIBEIRO, 2012, p. 52).

A "eurocentricidade" é um ideologema. Ideologema é um conceito operativo auxiliar do "miticiano" (expressão querida a Gilbert Durand) forjado na base heurística do conceito durandiano de mitologema (tema mítico). A noção de "trajecto antropológico" explicita (como diz Jung) substantivos simbólicos, que são os arquétipos (designados de imagens primordiais em Tipos psicológicos). 0 trajeto é o europeu na América e os símbolos são essa premissa de ciência como forma exclusiva da sociedade ocidental. Esse "estado preliminar, a zona matricial da ideia" que são os arquétipos europeus de ciência. A imagem é uma ideia representa o compromisso pragmático do arquétipo imaginário (ARAUJO, 2010, p. 691). Esse pragmatismo expressa o contexto histórico atual que vive a ciência brasileira.

A epistemologia que é validada na academia é carregada deste ideologema que pode ser lido como um molde "afectivo-representativo, o seu motivo arquetipal" (ARAUJO, 2010, p. 691). Esse modelo explica igualmente os racionalismos e os pragmatismos dos "senhores" das ciências. O racionalismo carrega os seus "próprios fantasmas" onde o ideologema como um "complexo significante que articula e mobiliza, ao nível actancial (eu social da "tópica"), o sentido figurado (semantismo simbólico e afetivo-emocional) com as ideias-força veiculadas pelas ideologias (orientações mais conceptualizadas, mais abstratas e rarefeitas) e presentes em dado contexto histórico sociocultural" (ARAUJO, 2010, p. 692).

O ideologema resulta da interação das facetas arquetipal (símbolos primários-mitos) e sociocultural (ideologia-utopia) do imaginário, neste caso o imaginário de ciência ocidental, pura e capaz de orientar a tudo e a todos. Essa carrega um "discurso racionalizante, mediante as metáforas e alegorias, o fluxo de imagens arquetípicas provenientes do nível fundador - o inconsciente coletivo específico", que neste caso associo ao pensamento excludente do "eurocentrismo". O ideologema condensa, "pela via da racionalização ideometafórica, as imagens arquetípicas sob forma de símbolos e as figuras ideológicas, metafóricas, alegóricas e utópicas no nível racional" (ARAUJO, 2010, p. 692). Há aqui uma sedimentação da "tópica sociocultural" (Durand, 2002). Essa sedimentação se desenvolve ao "nível das atividades racionais e lógicas mediatizadas pelas conceptualizações, codificações jurídicas, ideologias, reflexões pedagógicas (no sentido também social do termo), utopias e epistemologias" (ARAUJO, 2010, p. 692). Este nível é o do "mythos" que assim pode dizer o que se deve fazer.

O ideologema aparece partindo do "sentido histórico (literal, próprio), situado no porto racional (superego social)", toma força na direção do "nível fundador (o designado "id" social ou antropológico), passando pelo nível actancial (ego social), com a tarefa de coletar os traços míticos, por meio dos diferentes sentidos". Sentidos esses que atuam na psique dos cientistas e docentes de pós-graduação. Assumem o contexto "alegórico, metafórico e anagógico", que permite premissas perpetuadas no "nível racional", tornando os sentidos verbais e discursivos das "imagens se substancializa" ou teatralizadas. O símbolo da erudição científica dos "senhores doutores" se "esconde por detrás da sua máscara, ou seja, teatraliza-se em forma de metáfora" (ARAUJO, 2010, p. 691692). Carregados deste ideologema as ações dos colegiados e coordenações dirigem os programas onde quem não se enquadra é excluído. 
Entendemos por ideologema a unidade significante mobilizadora de energias semânticas, ao nível do imaginário social, passível de traduzir e de articular as ideias-força (dimensão ideológica) e os traços míticos (dimensão mítica: mitologemas, mitos directores, estruturas míticas da Humanidade) [SILVA e ARAUJO, nota 97, 2006, p 206].

Essa a unidade "significante mobilizadora" de energias que criam ações pragmáticas e discursos, que se desenvolve nesse "imaginário social" que é a pós-graduação no Brasil. Essa energia produz as ideias-força, uma visão que posso interpretar da dimensão ideológica, que conduz estes grupos que estão encastelados nos programas de pós-graduação. Esses produzem seus próprios traços míticos. Uma dimensão mítica carregada de mitologemas que são modelos arquetípicos enriquecidos com elementos próprios dessa cultura da pós-graduação. Cultura que carrega o eurocentrismo como forma de conhecimento do mundo. Estes traços apresentam mitos diretores e estruturas míticas, que asseguram um sistema de significados que aparecem de uma origem europeia de ciência, a qual não se interessa pelo conhecimento advindo de outros campos do saber, que são aparentes aos negros/as, indígenas e quilombolas. Com isso geram uma infinidade de motivos levam a exclusão desses/as estudantes dos programas de pós-graduação. É fato que são raros os negros/as, indígenas e quilombolas, presentes nestes espaços. No entanto presenciamos, infelizmente, sua contínua expulsão dos mesmos. Aqui busco identificar quais as formas utilizadas para que isso aconteça.

As resistências às ações afirmativas, que hoje observamos no Brasil, em parte "se deve à ignorância e à desinformação, resultados do silêncio que a academia branca impôs a si mesma e à sociedade, durante mais de um século, sobre a sua realidade interna de exclusão racial" (Carvalho, 2004, p. 2). As desculpas são muito parecidas e indicam "falta de qualificação dos mesmos", mas em realidade a supremacia branca é o motivo. É uma distorção social evidente e provocada por mentes que tem como base sua própria constituição étnica, ou seguindo os padrões vigentes, onde o europeu é exemplo de qualidade e de performance educacional (Silva, 2016).

Verifiquei estudantes negros que foram os primeiros colocados nos processos de ingresso em turmas de pós-graduação, tanto ao nível de mestrado quanto de doutorado, e que depois de pouco tempo foram expulsos de seus programas, pois eram considerados "não aptos". Outra forma de exclusão, mesmo por ações afirmativas, quando estas existem, é não lhes fornecem bolsas de pós-graduação ou mesmo retiram deles/as as bolsas, quando recebidas, para dar a estudantes ditos "mais qualificados", que "por acaso" são brancos/as.

As coordenações dos programas sempre se colocam como vítimas das intenções das maiorias, que são os colegiados, majoritariamente compostos por docentes brancos/as que usam de sua qualificação (doutoramento) como imagem inexpugnável de sabedoria e poder. Argumentam que seus esforços não são igualados por aqueles que eles excluem, mas não percebem ou "não dão importância mesmo", que suas formações foram feitas por um contingente único de homens e mulheres brancos hetero normativos de origem, ou com formação baseada em uma ciência europeia e não afeita aos sistemas de pensamento dos grupos "tradicionais" da sociedade brasileira.

Após o censo racial docente na UnB, passei então a solicitar a ajuda dos meus colegas negros para conhecer a porcentagem de docentes negros em outras universidades públicas. Mesmo admitindo uma margem de erro nas amostragens por eles reunidas (e na verdade colocamos um porcentual de $20 \%$ acima do número encontrado), deparamo-nos com situações chocantes, como as da USP, Unicamp, UFRJ e UFRGS, instituições em que a proporção de professores negros não passa de 0,2\%; a da UFSCAR, de 0,5\% e a da UFMG, de 0,7\% (Carvalho, 2006, p. 3). 
A realidade acima exposta é superior a realidade da UFPel, que em 2017 entre 1800 professores/as não haviam 20 negros/as. Esta ausência constrói uma presença, que é branca e "eurocentrada" (ainda não temos um censo de professoras na UFPel). O estudante negro, indígena ou quilombola não se encontra representado e assim, muitas vezes, nem procura a realização de pós-graduação, por se considerar incapaz e sem espaço de trabalho. Quando entra nos programas a sua condição e exigência de transformação para o pensamento vigente sempre é imposta.

Nas afirmações de Flávio F. Demarco e Rosemar G. Lemos (2017) que acreditam que é evidente a discrepância entre a presença de negros/as (indígenas e quilombolas) na sociedade brasileira e no Ensino Superior. Esses defendem com base na UNESCO, a "equidade à educação superior de qualidade", percebem isso dentro de uma qualidade e compromisso social da Universidade. Destacam que a Resolução 05/2017 do Consun/UFPel é parte de uma política mais ampla visando a permanência e acompanhamento dos estudantes negros e indicam o compromisso da administração da IES com a busca incessante pela equidade racial, e esperam que tudo se faça para um dia ver o "racismo institucional ... finalmente sepultado".

Os/as estudantes - negros/as, indígenas e quilombolas, cotistas ou não, só serão merecedores na escala que os regula, quando o dito "bem da ciência" for atingido. Ciência que é branca - hetero normativa - "eurocentrada", cujas formas de tratamento são excludentes, pois estes/as estudantes (diferentes) são tratados por uma regra onde se indica que sejam capazes de cumprir "os critérios estipulados pelo colegiado", que tem uma única forma. Estes critérios, insistem os docentes, são "conhecidos de todos", e assim "avalizam" o mérito da exclusão (Vieito, Munhoz, Andréa, 2018).

Os/as estudantes, para manterem suas bolsas e vinculação aos cursos de pós-graduação, muitas vezes se exoneram de cargos públicos ou privados, pois lhes é sempre cobrado "dedicação exclusiva". Presos então ao programa, que lhes impõem os processos disciplinares, ficam marcados pelas frustrações, o que ocorre em grande parte dos pós-graduandos. No processo de execução de avaliações estes são desligados dos programas, sem a menor sensibilidade aos esforços desenvolvidos pelos/as estudantes negros/as, indígenas e quilombolas para conseguir a vaga nesse universo.

A meritocracia como medida de sucesso e justificação de posições sociais perpetua-se e
encontra-se incrustada no ideal de todas as classes sociais. Trata-se de construção elitista que,
inconscientemente, é reproduzida, vitimizando as classes mais baixas e afastando a razão de
fracassos em função do próprio sistema desigual persistente no capitalismo, o que impinge o
fracasso aos grupos estigmatizados, no que se refere à mobilidade social - tão somente - em
razão de deficit intelectual, preguiça, em suma falta de "dom" ou, ainda, de esforço para "vencer
na vida" (Vieito, Munhoz, Andréa, 2018, p. 36).

A palavra "mérito" é uma medida norteadora das avaliações dos docentes, sem esta não há posições a serem tomadas no campo da ciência "eurocêntrica". Essa noção de mérito está "incrustada" no espaço acadêmico e é balizadora das formações. As elites acadêmicas são mantenedoras desse "sistema desigual" que é originada no "capitalismo", o capital intelectual que uns possuem e outros nem podem possuir. A ideia de "fracasso" aos que não tem mérito, e este mérito é exclusivo de um grupo, possibilita a estigmatização dos não-brancos. Justifica-se por um dito "déficit intelectual", uma "preguiça", uma "falta de dom", mas que é, em realidade, uma invenção de um grupo dominante na análise dos outros. Há um tipo de saber que é superior ao saber do outro.

O "mérito" impõe o que o outro deve ser, mesmo que não seja. "O principal problema do conceito da meritocracia é que ignora a trajetória, as barreiras que foram enfrentadas para alcançar o sucesso, valorizando-se apenas o ponto de chegada" (Vieito, Munhoz, Andréa, 2018, p. 36). Os colegiados 
indeferem os pedidos que discutem estes méritos, constantes indeferimentos feitos aos/as estudantes são baseados em alegações orais (dos colegiados), tais como: "não é permitido", "não é aceito", e outras formas. Formas estas que carecem de qualquer base legal ou regimental para tanto. Os regimentos dos cursos, os regimentos gerais de pós-graduação e os regimentos das Universidades Públicas Federais ou Estaduais, não apresentam bases para as representações feitas pelos docentes e não apresentam bases para as reclamações feitas para estes estudantes diferenciados, pois a base é fruto de um saber tácito. Este saber se constitui a partir de um saber racista.

A própria universidade e seus intelectuais, compostos em sua quase totalidade por brancos, produz saberes, de forma a excluir os intelectuais negros desse espaço. Não se pode esquecer que muitas formas de se pensar os negros são provenientes do discurso científico do século XIX, produzido a partir das teorias raciais europeias. $\mathrm{O}$ racismo explicado pela ciência foi a forma de manter a desigualdade de tratamento entre brancos e negros, naquele momento histórico (Vieito, Munhoz, Andréa, 2018, p. 40).

As coordenações com base nos colegiados sem base legal apresentam sempre negativas as solicitações constantes destes estudantes. Os interesses dos/as estudantes, por não prever proveito nas indicações dos colegiados, são menosprezados/as. As questões são tratadas de forma sumária em documentos de respostas, com textos (que podem ser sumariamente refutados) como: "é uma disciplina obrigatória" - mas o/a estudante pelo regulamento poderia cursar a qualquer tempo; "ele/a é bolsista do programa" - mas ser bolsista não impõe a escolha de disciplinas pelo colegiado a serem cursadas, podendo ser cursada depois, e assim por diante; "as regras são claras" - mas evidentemente elas não existem regras escritas, mas apenas nas cabeças racistas dos/as que as proferem. Como o/a estudante não consegue cumprir estes ritos sumários este/a é desligado/a. As coordenações afirmam, com base nos colegiados, que há um número certo de créditos a serem cursados, "são regimentais" e que os/as estudantes deveriam realizar, mas os regimentos muitas nem dizem nada sobre isso, ou permitem a escolha aos estudantes.

A professora Maria de Fátima Cóssio (2008, p. 113) indica que a mediação pedagógica, que é o ato de efetivação do/a docente na relação com seus educandos, necessite de uma "postura ética, que valoriza a pluralidade de idéias, que entenda a diversidade de idéias, que prefira a contradição, o dissenso à aceitação passiva de verdades pré-estabelecidas e de um padrão estereotipado de aluno, (...) a postura política é a postura ética e inclusiva". Sandramara Chaves (2017) aponta que a avaliação deve ser mais que aferição e classificação, punição ou mero instrumento de controle ou expressão de poder, percebe que esta tem se apresentado como no ensino superior de forma não isenta, dos problemas mais gerais constatados nesse campo e que, tanto na teoria quanto na prática, a avaliação nesse nível de ensino se reveste de rituais e atitudes discriminatórias. Mas entende a avaliação deve ser mediadora como possibilidade de acompanhamento contínuo e gradativo da aprendizagem do/a estudante, e enfatiza, assim como a Professora Fátima Cóssio, em curso de Pedagogia Universitária na UFPel, manhã do dia 20 de junho de 2017, que a avaliação deve ser entendida como um processo contínuo e dinâmico, ou seja que deve ocorrer durante a aprendizagem e não após como se fosse um produto. Essas ideias não são seguidas pelos colegiados, pois os programas são compostos por pesquisadores e por excelência se colocam muito distantes do "ato pedagógico" e do reconhecimento das particularidades dos grupos indígenas, de negros/as e quilombolas.

Outro caminho institucional de exclusão é a interação, ou falta dela, do/a cotista ou negro/a, indígena ou quilombola, com o/a orientador/a designado/a pelo programa, não manutenção do/a orientando/a 
em nenhuma linha definida de pesquisa, pois linhas ligadas às questões dos/as afro-americanos/as ou indígenas não são comuns nos programas. Os/as coordenadores dos colegiados colocam em atas estas impossibilidades de orientação e desenvolvem em conjunto com os/as colegas docentes os afastamentos, ou o empecilho na busca de coorientação ou uma orientação mais aproximada à investigação proposta pelos/as estudantes.

Realizam indicações, mesmo daqueles/as que provocaram os conflitos (entre o/a estudante e seu tutor/a). Os colegiados definem que as orientações seriam discutidas depois com os estudantes, que de alguma forma tentam reverter esses processos, o que jamais acontece, e quando acontece o tratamento é sempre degradante para o/a estudante. As orientações "não discutidas" com os/as estudantes é muito comum, sendo que o/a mesmo/a é conduzido/a para um caminho que originalmente não pensava. E é assim aos poucos expulso do programa por não ter como conduzir seu trabalho por um caminho não escolhido, mas imposto pela orientação.

As perguntas dos/as estudantes aparecem, mas as respostas dos colegiados não, ou são pouco esclarecedoras. A resposta comum das coordenações é que existe demanda excessiva entre os/as orientadores/as da linha de pesquisa do/a estudante, mas nenhum documento comprobatório "desse excesso" aparece em documento algum e muitas vezes contradiz afirmação de que serão garantidos os direitos dos/as estudantes. Ás vezes os direitos não serão garantidos "pelo excesso de trabalho" dos/as orientadores/as, isso tratado como justificativa.

As orientações indicadas pelas coordenações dos programas estão afirmadas nas capacidades de análise da produção do/a estudante, e quando este produz um texto para publicar, ou para um componente curricular, ou no contexto da dissertação ou tese, a análise dos/as orientadores/as designados/as são sempre inferiorizantes ou mesmo degradantes, sem considerar o processo de formação do/a estudante. Chegam a afirmar que estes/as estudantes não são capazes de investigar. Ou mesmo os/as próprios/as orientadores/as se colocam na posição inversa, de que não se sentem capazes analisar os textos "por excesso de trabalho", "por desconhecimento do tema" e assim por diante.

As trocas de orientação são feitas em sua grande maioria a revelia do/a estudante, e assim o processo se repete com o/a novo/a orientador/a. As coordenações afirmam que tratam da troca de orientação e essas são "independentes do fato gerador", mas é evidente que o afastamento de orientação é gerado pela "escolha impositiva da orientação", feita pela coordenação, e torna-se um fato cíclico.

As relações com as orientações são truncadas e os/as estudantes não recebem apoio, a falta de relação é jogada para o institucional. Sendo institucional o racismo institucional se estabelece e não soluciona estes problemas, pois em realidade as pessoas não querem resolver os problemas, pois acreditam "natural" a sua forma de pensar. Os documentos produzidos destas "relações nefastas" são transformados em trocas de contatos, onde os apoios sobre as referências de investigação, sobre os projetos e as demais questões são sempre tratadas como "falta de interesse" dos/as estudantes em mudar o seu curso. É evidente que se o/a estudante ao mudar o seu curso ele/a estará seguindo o curso da exclusão em sua grande maioria, pois normalmente é indicada que ele/a deva produzir o que o/a professor/a agora "(des)orientador/a" quer.

Os regimentos não tratam destas possíveis indisposições, os colegiados alegam que por não estar no regimento "não tem o que fazer", o que sobra aos estudantes é não realizar o texto, não apresentar 
o texto a uma revista, não terminar o trabalho de dissertação ou tese, ou seja, leva o/a estudante a evadir do programa. Os/as orientadores/as deveriam assessorar os/as estudantes nos trabalhos científicos. O que os/as estudantes percebem é que há um interesse deliberado de lhes retirar as bolsas, os créditos, as possibilidades de avanço na escrita.

Os impasses com os/as estudantes são solucionados na maioria das vezes de forma sumária, pois os programas não possuem grupos, ou comissões, ou outros órgãos de proteção à diversidade. As questões relativas a estes impasses não são levadas pelos/as orientadores/as e sempre se tornam temas das coordenações, que em não havendo respaldo nos regimentos nada fazem, ou se fazem o fazem contra os/as estudantes.

Quando os/as estudantes pedem apoio estes/as docentes indicam que "devem se dedicar mais", mas não dizem como, não apoiam, pois são categóricos, "eu não oriento essa proposta", mesmo que os textos sejam ligados diretamente às propostas de dissertação ou tese dos/as estudantes. As orientações tentam transparecer uma normalidade nestas relações, com afirmações de que "por meio da coordenação serão contornados os impasses". O que transparece nas afirmações das coordenações é que além do impasse, "seria mais conveniente e proveitoso a todos", que os/as estudantes seguissem as orientações ou aos colegiados. Essas afirmações são textuais constantes das atas dos programas. O que ocorre também é que muitos estudantes são levados a mudar de orientação por três ou quatro vezes, por não seguir ou adequar-se aos processos regimentais expostos pelos colegiados.

Os processos de exclusão seguem outros caminhos com afirmações que os/as estudantes que pediram revisão de notas a coordenador/a do programa, teriam revisões realizadas e em realidade a nota lhe seria atribuída pelo excesso de "faltas" que "não foram justificadas, o que demonstrou pouco comprometimento e preocupação quanto ao quesito frequência no componente curricular", muitas vezes o/a estudante não teve problemas de frequência, pois lhe é facultado legalmente ter até $25 \%$ de faltas. Parece absurdo, mas aparecem nos textos de atas essas afirmações. Muitas vezes as faltas haviam sido acordadas com a coordenação ou mesmo com os/as professores/as, mas que se valem delas para afirmar um descompromisso do/a estudante.

Várias vezes os/as estudantes solicitam documentos, necessários a comprovar presenças em atividades várias, mas que não são atendidas pelas coordenações ou colegiados dos cursos, espécie de "exclusão institucional" no fornecimento dos documentos que the era de direito. O/a estudante leva a público essas preocupações e assim é "taxada" de insubordinada e agressiva pelos pares brancos/as e professores/as do programa. Sofre então a exclusão dentro do próprio programa, não conseguindo realizara atividades em grupo e sendo isolado/a. Os colegiados se omitem nestes casos, as coordenações alegam "que isto não é feito desta maneira", mas não são apresentadas outras formas de reinclusão dos/as que são isolados/as por combaterem a exclusão.

As coordenações afirmam que o/a estudante "manipula as informações", mas o que ocorre em todos os momentos é que o/a estudante afirma e apresenta documentos comprobatórios de suas afirmações, mas que são menosprezados pelas coordenações e órgãos da instituição. No entanto as coordenações não entregam os documentos pedidos e afirmam que "estes sempre estiveram disponíveis". Mas quando os/as estudantes abrem processos e demonstram que são menosprezados pelas coordenações que alegam: que devido a "períodos dedicados a greve" ou "ocupações com a instituição", "não houve tempo hábil" ou "não funcionou o programa", entre outras alegações. 
As exclusões muitas vezes analisadas pelas comissões superiores aos colegiados, onde são sempre referendadas, reforçando o racismo institucional, pois nestas comissões e conselhos não há representatividade dos/as estudantes negros/as, indígenas ou quilombolas. Os superiores muitas vezes não analisam o todo e dividem em parte as questões para dar ganho de causa aos colegiados, muitas vezes de forma corporativa. Mas como estas análises nas comissões e conselhos são mais demoradas e os prazos são bem menores junto às agencias de fomento e nas próprias regras dos cursos, os/as estudantes acabam sendo prejudicados/as nas análises, pois os prazos passam e as questões são proteladas a prazos insolúveis. Muitas vezes os próprios conselhos reconhecem a exclusão, na relação com a orientação, na justificativa das faltas, na construção dos textos, mas dão ganho de causa aos colegiados numa contradição inexplicável. Consecutivamente essas comissões e conselhos acatam as solicitações dos colegiados, nas alegações de não haver "bases para afirmar a discriminação étnico-racial", indicam os arquivamentos dos processos.

O racismo institucional se instala, há indícios fortes de discriminação étnico-racial na distinção, exclusão, restrição ou preferência. O/a estudante em questão é negro/a, indígena ou quilombola. Esta distinção nunca é levada em conta, mas deveria ser. O racismo institucional é feito quando as instituições atuam no sentido de não prover um serviço, na formação educacional inadequado. 0 racismo se manifesta em formas de abordar as normas, ao colocar o/a estudante em situação de desvantagem no acesso aos benefícios gerados pela instituição, tais como sua permanência nos programas de pós-graduação, no fornecimento de bolsas de estudo, entre outros.

A Lei Federal no 12.288, de 20 de julho de 2010, que cria o Estatuto da Igualdade Racial, determina que o poder público federal instituirá, na forma da lei e no âmbito do Executivo - Ouvidorias Permanentes em Defesa da Igualdade Racial -, para receber e encaminhar denúncias de preconceito e discriminação com base em etnia ou cor e acompanhar a implementação de medidas para a promoção da igualdade. Por esta lei é assegurado às vítimas de discriminação étnica o acesso aos órgãos de Ouvidoria Permanente, à Defensoria Pública, ao Ministério Público e ao Poder Judiciário, em todas as suas instâncias, para a garantia do cumprimento de seus direitos. A Lei determina que as instituições públicas mantenham instrumentos para aferir a eficácia social das medidas previstas (nesta Lei) e efetuará seu monitoramento constante, o que não ocorre. Neste sentido as comissões de diversidades são fundamentais nas instituições cursos de pós-graduação e graduação.

A Lei Federal no 12.288/2010, indica que a discriminação racial ou étnico-racial é toda distinção, exclusão, restrição ou preferência baseada em raça, cor, descendência ou origem nacional ou étnica que tenha por objeto anular ou restringir o reconhecimento, gozo ou exercício, em igualdade de condições, de direitos humanos e liberdades fundamentais nos campos político, econômico, social, cultural ou em qualquer outro campo da vida pública ou privada.

O pensamento expresso no Estatuto é um novo ideologema, forte, mas que deve ser entendido assim quando discutimos as questões raciais, que envolvem as relações entre as pessoas no Brasil, pois ainda permanece a desigualdade racial, que para esta lei é toda a situação injustificada de diferenciação de acesso e fruição de serviços e oportunidades, nas esferas pública e privada, em virtude de raça, cor, descendência ou origem nacional ou étnica.

O estatuto indica também que o poder público promoverá ações que assegurem a igualdade de oportunidades para a população negra (indígena e quilombola) lograda mediante a adoção de políticas e programas de formação profissional, voltados para a população negra (indígena e quilombola), tais 
como a permanência em Programas de Pós-Graduação. Ao fazê-lo, como determina a Lei, pelo poder público, proporcionarão ações com o objetivo de elevar a escolaridade e a qualificação profissional dos negros/as, indígenas e quilombolas.

Laura Cecilia López (2017) identifica que o racismo institucional é feito quando as decisões consideram a raça do indivíduo, sendo que estas decisões tentam subordinar um grupo racial. Este racismo é feito tanto de forma aberta como velada. A forma velada se faz apresentar quando o indivíduo sujeitado ao racismo institucional, quando se implementa e coloca em funcionamento das forças consagradas da sociedade, regulamentos e estatutos, este processo de racismo é desenvolvido na reprodução de políticas institucionalmente racistas, o que torna difícil de responsabilizar os agentes promotores deste racismo. O que não é feito de forma explicita, mas é recorrente ao atingir sempre aos negros/as, indígenas e quilombolas.

O racismo institucional é feito quando as instituições e organizações atuam no sentido de prover um serviço profissional inadequado para às pessoas em virtude de sua cor, cultura, origem racial ou étnica. Na realidade o racismo institucional se manifesta em formas de abordar as normas, práticas que são resultantes do preconceito racial, uma atitude que combina estereótipos racistas, falta de atenção e ignorância. O racismo institucional sempre coloca pessoas de grupos raciais ou étnicos discriminados em situação de desvantagem, no acesso a benefícios gerados pelo Estado e por demais instituições e organizações.

O imaginário dos programas de pós-graduação é carregado das imagens, sob a forma de mito dos "senhores da ciência" (racista, machista e heteronormativa) carregada de símbolos e metáforas, que se reproduzem em alegorias forjadas pelo ideologema eurocentrado. São metamorfoses da "formação" dos cientistas que se sedimentam em uma imaginação que visa muito particularmente o tema da "ciência ocidental". Confecciona imagens que povoam as mentes "brilhantes" do imaginário educacional na pós-graduação do Brasil. O imaginário que pode por vezes não ser educacional, pois é um "imaginário degradado, isto é, espartilhado por uma retórica racionalizadora que faz com que ele não possua a riqueza semântica própria das grandes metáforas vivas, dos grandes símbolos, dos mitos" (ARAUJO, 2010, p. 697). É imaginário de uma pretensa unicidade, como se todos fossem iguais aos europeus, carregado de discurso conceitual "e, consequentemente, empobrecido do ponto de vista mítico-simbólico" da população brasileira (ARAUJO, 2010, p. 697). A mítica do Brasil foi assim expressa por Durand (1996, p.204) uma "unidade na diversidade (...) multicultural". A questão é que este imaginário desenvolvido no povo brasileiro é negado na pós-graduação.

A proposta da universidade moderna que se instala no Brasil, e se perpetua até hoje é aquela levantada no Humboldt no século XIX (MORIN, 1997). Destinada a multiplicar a ciência, que se estabelecera em meados do século XIX. Ela deveria fazer coexistir, "infelizmente apenas coexistir e não comunicar", a "cultura das humanidades" e aqui indica que a humanidade era a europeia e ocidental e a "cultura científica". A "atitude de pesquisa" deveria ser o caminho desta Universidade e assim por excelência o dos pós-graduações. Deveria "adaptar-se a modernidade científica e integrála". "Responder às necessidades fundamentais de formação, fornecer professores às novas profissões técnicas e outras... mas também fornecer um ensino metaprofissional, metatécnico" (MORIN, 1997, p. 18), ou seja, distante das humanidades (mesmo que ocidentais) e mais distante ainda das sociedades tradicionais ou sistemas comunitários de comunhão, comuns as populações negras, indígenas e quilombolas. Esse tipo de universidade é a nossa atual, que cria e recria seus pósgraduações. 
Alberto Araujo (2010) solicita então que se recorra a "uma hermenêutica adequada a este tipo de imaginário", que através mitanálise amplie a capacidade de compreender esse novo mundo que se coloca a frente do docente, um "modelo hermenêutico não se limita tão-somente a recolher e a tipificar o feixe de figuras presentes nos textos da tradição educativa ocidental", mas que supere esta construção catalográfica do conhecimento e de sua reprodução. "Esta hermenêutica, como ato interpretativo que é, visa restaurar o sentido existencial veiculado pela tradição das grandes imagens pregnantes simbolicamente" (ARAUJO, 2010, p. 698). Essa nova perspectiva deve restituir de novo "o olhar oximorónico àquele que se interessa pela educação e que se constitua numa espécie de comunidade interpretativa". Olhar e ação que cria uma nova "fraternidade iniciática e um encontro de discípulos" onde estudantes e "mestres devem em conjunto cultivar uma racionalidade crítica imaginativa e uma imaginação dotada de um olhar racional crítico" (ARAUJO, 2010, p. 697-698). Esse olhar é necessário para evitar a continuidade do racismo institucional que expulsa os diferentes, considerados "anormais", dos programas de pós-graduação.

\section{REFERÊNCIAS}

ARAÚJO, Alberto Filipe \& RIBEIRO, José Augusto: As Aventuras de Pinóquio à luz do Imaginário Educacional. Revista Lusófona de Educação, Lisboa, n 22, (pp. 39-53), 2012

ARAUJO, Alberto Filipe Ribeiro de Abreu. Quando o imaginário se diz educacional. Revista Brasileira de Estudos Pedagógicos, Estudos RBEP. Brasília, v. 91, n. 229, p. 679-705, set./dez. 2010.

CARVALHO, José Jorge de O confinamento racial do mundo acadêmico brasileiro. Série antropologia 395. Brasília 2006. Disponível em http://www.dan.unb.br/images/doc/Serie395empdf.pdf.

CARVALHO, José Jorge de. As ações afirmativas como resposta ao racismo acadêmico e seu impacto nas ciências sociais brasileiras. Série antropologia. 358, Brasília 2004 disponível em http://www.dan.unb.br/images/doc/Serie358empdf.pdf

CHAVES, Sandramara M. Avaliação da aprendizagem no ensino superior: realidade, complexidade e possibilidade. - UFG GT: Didática / n.04 , disponível em http://www.estef.edu.br/zugno/wpcontent/uploads/2011/03/avaliacao1.pdf acesso em junho de 2017

CósSIO, Maria de Fátima. Políticas institucionais de formação pedagogica e seus efeitos na configuração da docência e na qualidade universitária : um estudo sobre as IES comunitárias do RS. (Tese de Doutorado), disponível em http://www.lume.ufrgs.br/handle/10183/13275 acesso em Junho de 2017

DEMARCO, Flávio F.; LEMOS, Rosemar G. Acesso afirmativo na pós-graduação da ufpel, qualidade $e$ equidade. Diário Popular, 3 de junho de 2017, disponível em http://www.diariopopular.com.br/index.php?

$\underline{\text { n sistema }=4080 \& i d}$ noticia $=$ MTIONDUz\&id area $=$ NA\%3D\%3D, acesso em junho de 2017

DURAND, Gilbert. As estruturas antropológicas do imaginário: introdução a arquetipologia geral. São Paulo: Martins Fontes, 2002.

DURAND, Gilbert. Campos do Imaginário. Lisboa: Instituto Piaget, 1996

Estatuto da Igualdade Racial - LEI NO 12.288, DE 20 DE JULHO DE 2010. disponível em http://www.seppir.gov.br/portal-antigo/Lei\%2012.288\%20-

\%20Estatuto\%20da\%20Igualdade\%20Racial.pdf acesso em junho de 2017. 
LÓPEZ, Laura C. O conceito de racismo institucional: aplicações no campo da saúde. (original publicado em Comunic., Saude, Educ., v.16, n.40, p.121-34, jan./mar. 2012), disponível em http://www.scielo.br/pdf/icse/v16n40/aop0412 acesso em junhoi de 2017.

MORIN, Edgar. Imaginários da educação: por uma reforma da Universidade e do pensamento. Revista Famecos, Porto Alegre: PUCRS, (pp. 17-20), v. 4, n. 6, 1997

REGIMENTO GERAL DA UNIVERSIDADE, (UFPel), Processo MEC n² 209.559-77sso CPE no 5543-76, Parecer CPE no 553-77 disponível em http://wp.ufpel.edu.br/scs/regimento/, acesso em junho de 2017.

SILVA, Armando B. Malheiro da \& ARAÚJO, Alberto Filipe. Para uma mitanálise da fundação sagrada do reino de Portugal em Ourique. Estudos em homenagem ao Professor Doutor José Amadeu Coelho Dias, vol. 1, p. 177-208, Lisboa/Porto: U. Porto, 2006.

SILVA, Marcos A. B. da "Trajetórias e Mobilidades educacionais de negros na pós-graduação (mestrado). Projeto História, São Paulo, n. 56, pp. 451-462, Mai.-Ago. 2016

VIEITO, Ana Carolina Esposito; MUNHOZ, Danielle Duarte; ANDRÉA, Gianfranco Faggin Mastro. Elites e Poder no Campo Científico: a Questão das Cotas para Negros na Pós-Graduação Stricto Sensu no Brasil. Revista Ciências Jurídicas, v.19, n.1, p. 35-41, 2018. 